\title{
ÇOKKÜLTÜRLÜLÜK, TÜRKIYE VE YENI DÜNYA DÜZENİ
}

\author{
Prof. Dr. Doğu ERGtL*
}

Örgütlü olmak, bireyleri güçlendiren bir olgudur. Bu nedenle Türkiye'de insanlar, ozgür olsalar bile gụ̧̈lü deģildirler. Üyesi olduklan mesleki, kültürel, siyasal ơrgüler (dernekler, kuruluşlar, sendikalar) aracılığıyla sisteme kaulmakta zorluk seken, bu konuda engellenen insanlar, tekil olarak ihtiyaçlannı karşılamak ve mutluluğu aramak durumunda kalıyorlar. Tek başlarına kalınca en temel ihtiyaçlarını karşılamaya yőneliyorlar. Maddi doyum öne çıkıyor. Ekonomik kazanç arayışı, çợu kez kişisel yeteneklerin ve yaratıcılığın tek uğraş alanı haline geliyor. Ondan sonra da, kendi bencil dürtuleriyle hareket eden, sürekli olarak kendi geleceklerini düşündükJeri için birlikte hareket etmeyen bir insanlar topluluğu ortaya çıkıyor.

$\mathrm{Bu}$ durumun farkında olan çeşitli kümeler, grup ruhunu ayakta tutmak için insanlan en radikal davranış biçimlerine yönlendiriyorlar. Varlıklarını, ne biçimde var olmak istediklerini topluma duyarmak, farklılıklarına dikkat çekmek amacıyla silahı politikaya baş vuruyorlar. Böylesine radikal bir belirtim biçimi, ne azık ki çokkültürlülügüu, silah seslerinin gürültüye boğduğu bir kakafoniye dơnüştürüyor. Siyaseti içinden çııılmaz bir hale sokuyor.

Silahlı politika, aydınlarla halkın arasını açıyor. Aydınlar istemlerini, gorüşlerini, düşünceler, ideolojilcr ve barış̧ı yollarla topluma aktaran, onlara yön vermek isteyen bir sosyal tabakadır. Alt tabakalar ise, istemlerini ancak örgüllülükle duyurabiliyorlar. Aydınların bircyscllił̧i belki onların gücü, fakat alı tabakaların örgütsüzlüğ̈u, onlann güçsüzlcuk kaynağıdır. Yine de alt tabakalar, bireysel çabalarının defaatle yetersiz kaldıłıı kanıtlandıktan sonra örgütlenebiliyorlar. Örgütlendikten sonra bile demagogların, halkhatiplerin oyuncağı olabiliyorlar.

Demagogların peşinden sürüklendikleri sürece alt tabakalar ile aydınlar arasındaki sağlıklı ilintiler kurulamıyor. Aydınlar, kent ortamının bireyselliğini kınp, ne kendileri orgütlenebiliyorlar, ne de kitleleri ơrgütleyebiliyorlar. Dolayısıyla, çokluğu, çoğulculuğa

\footnotetext{
*.O. Siyasal Bilgiler Fakültesi, Ogrretim Oyesi
} 
dőnüştüremiyorlar. Bu koşullar altında, yơnsüz ve óndersiz alttabakalar, inanç onderlerinin, radikal akımların peşine takılıp yerleşik kurumları ve toplumlan istikrarsızlığa sürüklüyorlar.

Aslında, sonuçları olumsuz da olsa, bőylesi bir toplumsal hareketlilik, çok kültürlülüğün ürünü. Çünkii, farklı yaşam biçimlerinin, farklı yaşam algılarının ve belirtimlerinin dinamizmini yansıtıyor. Ama, şekillendirilmediği, yasal ve kurumsal kalıplar kazanmadığı için düzensiz, orgütsüz ve kuralsız olarak sisteme yansıyor.

Işte bu dinamizm, sürekli bir kakafoni değil bir "toplumsal senfoni" haline getirilebilirse, toplumsal "çokluk", siyasal çoğulculuğa" dönüştürülebilir. Diğer yandan, toplumia çogulculuk doğrultusunda yeterince güçlü talepler olmayabilir. Orgütlü kümeler, sadece kendi dar çıkarlarını tatmin etmeyi ve ve maddi edinimlerini artırmayı birinci hedef olarak görebilirler. Bu durumda, bencil bir bireycilik, toplumsal sorumluluk gözetmeyen grupçuluk ve siyasal kabilecilik, toplum harcını "ufalar", ayrıştunır. Bu durum, kişiler-arası illişkilere "ahlak erozyonu" olarak yansır. Ne yazık ki, biz şimdi bu talihsiz evreye girmiş bulunuyoruz.

\section{Kümeler (Gruplar), Toplum Kumaşının İlmikleridir}

Aileden sonra toplumsal örgütlenmenin birincil örnekleri olan gruplar, insanlan yalnizlıktan, yetersizliğin verdiği aşağılık duygusundan, tecrit edilmişlikten, hareketsizliğin alışkanlık haline gelmesinden ve ahlaki boşluktan kurtarırlar. Bireylerin once "adlandırılabilir" bir kürnenin üyesi olmalarını, sonra da sayısız kümenin toplamı olan bir ulusun üyesi olmalarını sağlarlar. Insanlar, bu karmaşı üyelikler bağı içinde alt ve üst kimliklerini bulurlar veya edinirler. Kişilik kazanırlar.

Toplumsal örgütlenmenin üst (devlet) ve alt (kümeler) katlan arasında muhakkak bireye bir ozgürlük ve yarathcılık alanı bırakılmalıdır. Küme ve siyasal aidiyetlerin, bireyselliği (bencil, "her koyun kendi bacă̆ındạn asılır" bireyciliği değil) öldürmesine izin verilmemelidir. Otoriterliģin ve bencillikten kaynaklanan ahlaksızlığın (topluma karşı sorumsuzluğun) debisi ancak böyle düşürülcbilir.

Modern toplum, bireysellikle, grupsallık arasındaki dengede oluşmuştur. Bu denge korunmalıdır. Çünkü sınırsız özgürlüğün, demokrasi yaratmadığı anlaşılmışır. Diğer yandan, grup kimliklerine hapsedilmiş ve grup normlarının dışına çıkamayan bireyler, belki kendilerini güvende hisssederler. Ama onlar, hiç bir zaman özgürleşemezler. Bu yüzden de kişilikleri güdük kalır, bir sürünün üyesi olmayı aşamazlar. Bölünmüş, bölümlenmiş (komparımantalize) toplumların birbiriyle çatışan kümelere ayrışması olgusuna verilen ad olan "yeni-kabileciliģinn" köklerinden birinin bu olgu olduğu ileri sürülebilir. Pekiyi, ơrgütselliğin gücü ile bireysel ठzgürlüŭgü bir àrada yaşalmak için ne yapmak gerckir?

Çare, kültür kümeleririn muhakkak şeffaflaşmasıdır. Onların, örf ve adetlerini, kültürlerini yaşama tarzlarını "açığa çıkarmaları", resmen teşvik edilmelidir. Kendi anlayışları doğrultusunda, dinsel cemaatlerini oluşturmaları, hastanelerini, gündüz bakımevlerini, yaşlıevlerini kurmaları; varsa okullarında, yoksa özel eğitim yoluyla kültürlerini ve kültür dillerini çocuklarına oğrctmeleri sağlanmalıdır. Çünkü, kültür kümelerinin, kendi geleneklerine, alışkanlıklarına göre insan yetiştirme, yaşlılarla ilgilenme, üyelerini eğiıme gibi istek ve çabalan hcp varolagelmiştir. 
Bu girişimlerin sonuçlarından kuşku duyanlara sorulmalıdır: "Hoşgörü ve farklılıkların sergilenmesi, toplumu atomize eder, yani onu böler mi? Yoksa, başka türlü ortaklık kuramayacak ve bir ortaklık anlayışı geliştiremeyecek topluluklan, oluşmasına katkıda bulunduklan bir toplumsal dokuda, hukuk sisteminde ve siyasal birlikte buluşmak daha mı gerçekçidir?" Asıl sorun budur...

Hür kültür kümesi, kendi özel ve ozgün yaşam alanını (coğrafi anlanda dę̧il) belirlerken, bu ozgürlügün güvencesi olan toplumun kollektif/ortak normlarını, istemlerini ve ihtiyaçlarını karşılamak yükümlülüğünü de üstlenir. Üstlenmek zorundadır. Çünkü, cemaatleri aşan bir toplumsal bütünlük sağlanamaz.

Toplumsal yaşamın geniş çerçevesini çizen, bireylere yurttaşlık hakkı ve sorumluluğu sunan, kollcktif normlar ve anayasal düzene vücut veren hukuk sistemidir. Toplumsal kurumlar, bu çerçevede yerlerini alırlar ve çalışırlar. Toplumun organik işbolümünínen mahrum hiçbir grup, ne kadar büyük olursa olsun, çağdaş yaşamda tek başına kendine yetemez. Bu yetmezlik, toplum çapında oluş(turul)an işbolümünün varlık nedenidir. $O$ nedenle, herbiri kendi yaşam alanlannı oluşururken, tüm yaşam alanlarınn ve tarzlarının güvencesi olan devletin ne demek olduğunu ve devlete bağımiılık sorumluluğunu bütün kümeler anlarlar. Bu anlayış, bir ulusun, olgunluğa eriştiğini gösterir. Artık, ulus-devletin doğumu hazır demektir.

Ulus-devlet, farklı etnik ve kültür kümeleri arasında varılan siyasal mutabakaun ürünüdür. Haklar kadar sorumlulukların potasıdır. Farklılıkların eklemlendiğgi, bütünleştiği tezgâhtır. Bu tezgâhta, sosyal kümeler, devletle ilişkilerinde siyasal alanı da belirginleştirirler. Sosyal kümelerin merkezle olan ilişkileri kurumsallık kazanır.

Sonuçta şరyle bir senaryo doğar: Bir zamanlann işyeri militanı, grevlerle protesto yürüyüş̧leri arasında koşuştururken, şimdi bir sendikanın sorumlu temsilcisi olarak, işcilerin haklarını savunur. Bunu yaparken, sistemin daha iyi işlemesine ve kendini düzelımesine katkıda bulunabilir. Aynı şekilde, bir dinsel veya etnik kümenin sokak eylemcileri, zamanla kendi gruplanının veya cemaatlerinin sözcüsü konumuna gelip. siyasal koalisyonlara girebilirler, kendilerine karma listelerde yer arayabilirler. Bunu yapuklan ölçüde toplumun ortak değerleri ve çıkarlan üzerinde fikir yürütmeye, orak eylem planları üzerinde uzlaşmaya başlarlar.

Bu gelişme son derece doğaldır. Çünkü, toplum ve onun sał̆ladığı "düzen" olmadan, hiçbir grubun kümesel ve cemaatsel haklarının ve çıkarlannın korunması mümkün değildir. Bu anlayışa varan kümeler ve temsilcileri, sosyal-kültürel çokluğun, ancak siyasal çoğulculuk ile sağlanabileceği gerçeğini er geç kavrayacaklardur.

Işte bu anlayış, merkezi otoriteyi güçlendirecek, toplum veya ulus bilincini pekiştirecektir. Bu bilinç, özel yaşam (kimlik) alanlarında özerk olan cemaat ve kültür kümelerinin, kendi özgül sorunlarının çözümü için çabalarken, gerek merkezi otoritcyle, gerekse birbirleriyle pazarlık etmesini, uzlaşmasını ve dayanışmasını sağlayacakur.

Gelişmiş ülkclerde bu, hep böyle olmuştur. Çokkültürlülük, ekonomik ve sosyal eşitliğin sadece ürünü değil, aynı zamanda onları yasal güvenceye kavuşturmanın programıdır da. Eğer bircysellik ile, herhangi bir topluluk (kültür veya soy kümesi) üyesi 
olma nitelikleri, birlikte işleyecek, birlikte varlıklarını sürdüreceklerse, bunlann siyaset hayatına da birlikte girmeleri gerckir. Bu birliktcliłin ne oranda sał̆lıklı ve demokratik olacał̆

\section{Grup (Küme) Dayanışması ve Etkinliği}

Grup yaşamı, tek başına, bireyleri edilginlikten (pasiflikten), yalnızlıktan ve birbirlerine yabancı kalmaktan kurtarmaz. Ne kurtarır? Gruplara amaç kazandırmak, bu amaç etrafında örgütlemek ve harekete geçirmek kurtanı. İşte devlet burada işin içine girer. Grupların ơrgütlenmelerine, çalışmalarına destek verir. Bunu yaparken, devlet, bütün gruplara aynı sesafede durur, eşit davranir. Farklı programlar yoluyla benzer toplumsal hedeflere varmalanna yardum eder.

Işte, birey, grup ve devlet üçlemesi qu birlikılik nokıasında kesişir. Bireysellik, sadece kendisi için olmak, kendisi için çalışmak bencillił̌ine düşmeden ancak küme aidiyeti yoluyla toplumsal düzeye ulaşabilir. Eğer gerçekten çoğulculuğu, çokkültürlüllüğü savunuyorsak, ne tek başına bireysciliği, ne de tek başına cemaatciliği veya grupsallıği yüceltmeliyiz. Böylece ne tek başına liberal, ne de tek başına "toplumcu" olmak zorunda kalınz. Bunun yerine hem bireyci, hem de (aynı zamanda) grubumuzun erdemlerini yücelterek, "liberal toplumcu" olabilme şansını yaratabiliriz. Ancak bőyle gerçek bir demokrat olabiliriz. Sadece yasal ve kurumsal anlamda değil, toplumsal anlamda, bir yaşam biçimi olarak demokrasiyi özümlcyebiliriz.

\section{Demokrasinin Önündeki Engeller}

Demokrasi, gruplar aracılığıyla ve grupların ctkin kaulımıyla oluşan bir rejimdir. Insanlık tarihi incelendiğinde görülür ki, kişilerin ve grupların kendi yerel, etnik, dinsel ve ulusal kimliklerini en dramatik biçimde ifade etuikleri zamanlar, bunalım donemleridir. Bu dönemlerde siyasal baskı ya üst noktadadır ya da baskının kaynağı zayıflamıştır. Göreli bir özgürlük ortamı doğmuştur.

Sözü edilen olguya en son örneklerden biri Sovyetler Birliği'nin tarih sahnesinden çekildiği şu son yıllardır. Bütün özgül küme kimliklerini ortadan kaldırmayı "evrensellik" olarak anlayan komünizm, bunca yıl bastırdıktan sonra bugün "yeni-aşiretler" biçiminde su yüzüne çıkan soy ve kültür kümelerinin sunduğu yerel ve özgül grup. kimliklerini tam anlamıyla anlamamıştır. Cünkü, evrenselliğe, bütün bu altkimliklerin bastırılması veya yok edilmesi yoluyla varılacă̆ını sanmıştır.

Ilginçtir ama, komünizm de "uluslararasıcılığı", tıpkı Habsburg ve Romanov hanedanlarının birçok ulusu, kendi imparatorluklarına tabi kılmalarındaki mantığa dayandırmışur. Komünistler, keyfi olarak yönetilen imparatorluk halklarının veya ulusal küimelerin, "şimdi neden komünizmin şemsiyesi alunda yaşamasında sakınca olsun" demişlerdir.

Tabii bőyle bir anlayıs, önünde sonunda iflas edecekti. Etti de... Simdi Bau'da yeni bir süreç işliyor: Avrupa Birliği kuruluyor. Sovyet boyunduruğunda yaşayan Doğu Avrupa halkları da kendi ulus-devletleriyle bu sürece kaulmak istiyorlar.

Yakından bakılınca, Batıda birlik arayışının iki ana olguya dayandığı görülür. Once, toplumlar, ulus-devletler olarak iç tutarlığa crişmişler, siyasal ve ckonomik olarak 
"rüştlerini isbat etmişlerdir". Simdi daha büyük siyasal ve ekonomik orgütlenmelerin çausı alunda daha müreffeh, daha güçlü ve güvenli olacaklanna inanıyorlar.

Diğer bir süreç de, Avrupa'da büyük (ve emperyalist) devletlerin egemenliklerinin sona ermesiyle pek sok tabi devletin bağımsızlą̧masıyla işlemeye başiamışur. Bu sürece "demokratikleşme" adını verebiliniz.

Zaman ilerledikge, demokrat olmanın bağımsız olmaktan çok daha zor olduğu anlaşılmışur. Iş başına geçen iyi niyetli demokratik yönetimler, demokrasiyi hayata geçirmeye çabalarken, "demos" yani halk deyiminin bir tek halk tarafindan temsil edilmediğini anladılar. Gördüler ki, her devletin çausı altunda birden fazla halk, yani külttir kümesi vardır...

\section{Demokrasinin "Inşą"}

Işıe gerçck demokrasinin "inşaa" bu anlayışla, yani tüm kültuir kümelerinin temsil edilmesi sorununun çözümü arayışı ile başladı. Bu doğrultuda hızlı ve etkin adımlar atamayan ülkelerde, kültür kümelerinin temsil krizi basgosterdi. Yugoslavya, Gürcistan gibi ülkelerde bu kriz, savaşa neden oldu. Çekoslovakya orneģinde ise halklar veya tarihsel-kült kümeler (Çekler ve Slovaklar), birbirlerinden barış içinde ayrnlıp kendi demokrasilerini kurdular.

Bütün bu deneyimler gőstermiştir ki, demokrasi, ancak kendi kendini yơnetebilen halklar sayesinde var olmuştur. Birarada yaşayamayan, yaşamak arzusu duymayan halkların arasındaki ilişki, uzlaşmacı ve banş̧̧ı olamaz, olamıyor. Birarada yaşamak iradesini körleten en ónemli eumen, tarafların birbirlerini siyasal eșitleri olarak gőrmemeleri, bu yüzden de birbirlerini egemenlikleri aluna almaya çalışmalandır. Bu uzlaşmaz zihniyet, kaçınılmaz olarak çauşmacı ve anti-demokratiktir.

Bir genelleme ile, "Batı'da demokrasi, uyuşămayan kümelerin birbirlerinden ayrılmasıyla doğmuştur" diyebiliriz. "Doğu"da ise, birbirleriyle uyuşamayan gruplann zorla birarada tutulması yüzünden demokrasinin gelişmesi gecikmiştir.

Pekiyi, tek çare aynımak mıdır? Hayır, o zaman dünya siyaset haritası an peteğine benzer, siyasal tarih de tek hücreli varlıkların mezarlığına dönerdi. Yapılması gereken, ulusal devletin, herkesin devleti olmasını sağlamakur. Bunun için onun "inşaına" ve yönetimine, bütün toplumsal kümelerin eşit olarak katılmalarının yolunu açmak gerekir.

Batı'da çokulusluluk, uluslarüstü örgütlenmelere dőnüşürken, Doğu'nun otoriter, hatıa diktatoryal siyasct anlayışı, bırakalım uluslarüstü birlikieri, gönülliü ulusal birlik yaratma endişesi bile taşımamışur. Doğu'da siyasetin dili de kurumları da, şiddetle yüklüdür. Bu nedenle, siyasal yapılar istikrarsız, meşruiyet sorunu hep gündemde, iktidarlar sallantıdadır. Böyle bir ortamda kalıcı uluslarüstü ơrgütlenmelere gitmek olanaksizdir.

Evct. Bat'da da önce güçlü devlellcr kuruldu. Ama ondan sonra güçlü toplumlar/ uluslar oluşturuldu. Güçlü bir devlet, ancak güçlü bir toplum ủzerinde ayakta durur. Doğu'da bu gerçek hiç anlaşılmadı. Devlet görece güçlü, milleı güdük kaldı. Dolayısıyla, aksine gơrüntü vermelerine karşın "doğulu" devletler hep güçsüz oldular. Bu nitcliklerini saklamak için şiddete başvurdular. Şiddet, her türlü özgürlüğ̈un gelişmesini engelledi. 
Ancak ozgürlük ortamında gelişebilen bilim, sanat, demokrasi ve hukuk kavruk kaldı. Otoriter devletler, ülkelerinin geri kalmasına neden oldular. Ondan sonra da "neden bizim ülkemizde gerici akımlar başgð̋steriyor" diye hayret euliler. Gericiliğin kaynă̆ının, ulusal gerilik veya gecikmişlik olduğunu, bunun ana nedeninin kendi buyurganlıklan olduğunu kabullenemediler.

Bat deneyinde, "ulustan önce" tarih sahnesine çıan güçlü devletler, birden fazla halkı kendi içlerinde bir süre zorla tuttuktan sonra, bu birlikteliğin ancak rıza ile olabileceł̌ini anlayıp, "ulusal bilincin" gelişmesine çalıştular. Iş̧te, once'ulus sonra demokrasi, bu çabanın ürünüdür.

Demokrasi, kendi kendini yőnetebilme olgunluğu ve becerisidir. Bugünün cokuluslu yapılan, demokratik toplumların birlikıliğinden dogmaktadır. Bu toplumlar, kendi içlerinde banşı saglayıp, demokratik siyasal yapılar geliştirmeselerdi, gönüllü olarak aralarında uluslarüstü bir örgütlenmeye gidemezlerdi. Pekiyi, bir ülke içinde toplumsal barışın (dolayısıyla demokrasinin) asgari koşulu ne? Bu sorunun en basit yanıu, toplumu/ulusu oluşturan kümelerin kendi günlük hayatlarını yönlendirmede özgür olmalandır. Başka bir deyişle, kamusal alanla, kültürel alanın birbirinden (ayn deģil ama) ozerk olmasıdır... Eğger toplumun "ilmikleri" olan kümeler, kendi içlerinde demokrat, yani üyelerinin günlük hayatlanın desteklerken özgür ve özgürlükçü iseler, o toplum demokratiktir. Gerisi sadece sözel yakışurmalardır.

Demokrasi evde başlar, kümeler içinde olgunlaşır; kümeler arasındaki ilişkilerde smanır, toplum düzeyinde somutlaşır ve devlet kaunda yasallaşır. Eğer, örgütlü kümeler, üyelerinin günlük hayatların kolaylaşırma ve haklarını güvenceya alma çabasında ơzgür değillerse, göstermelik kurumları olsa da o toplum demokratik değildir. Demokrasinin kurucu üyeleri, toplumsal kümeler ve onların temsili örgülleridir. Bu durum, birden fazla soy ve kültür kümesinin bir arada yaşadığı -çokkültürlü- toplumlarda daha da belirginlik kazanır.

Her çokkültürlü toplumda geçmişten günümüze miras kalmış bir takım çőzülmemiş sorunlar bulunabilir. Bunların çoğu psikolojiktir; kümeler-arası çekişmeler, yenilgiler, aşağılanmışlıklar, geçmişte yaşanmış acılar. Bunlar tam olmamışlarsa bile, öyle olduğuna ilişkin yaygın kảılar (basmakalıplar) olabilir. Bu olgunun, günümüzün insan ilişkilerini ve toplumsal barışın "kirletmemesi" son derece önemlidir. Tarih içinde oluşmuş olan olumsuz duyguların "kompleks" haline gelip, süren nefretlere đönüşmesi, ancak devletin toplumsal kümcler arasında eşit mesafede durması ile mümkündür. Cokkültürlü bir toplumda, etnik ve dinsel açıdan "milliyetçilik" yapmak veya resmen taraf tutmak, toplumsal barışın temcline konmuş bir dinamittir. Demokratik yönetimler ideolojik olarak tarafsız olmak durumundadır. Onların koruyacakları tek şey, demokrasinin esaslarıdır. Ancak bőyle bir yönctim anlayışı ile dünün anlaşmazlıkları, bugünün kavgalan biçiminde devam etmez; toplum, kendi tarihinin "mahpusu" olmaz...

Bugün artık yeni bir tarih yazmak durumundayız. Hem de büyük fetihlere ve keşiflere, dolayısıyla "imal edilmiş" efsanelcre dayanmayan bir tarih. Günün tarihi, kılı̧̣ ucuyla, kan mürekkebiyle ve fatihlerin buyrugu ile yazılmayacak. Yazılmamalı... Aklın terazisinde, bir kefede kitlelerin gereksinimleri, diger kefede bireyin ozgürlüğü dengelenmeli ve saptanan olçü, kara kaplı hukuk kitabına kaydedilmelidir. Öıçüm işlemini de, kayıt işlemini de ilk kez kendi tarihinin yapımına ve yazımına katılan halk 
yapmalıdır. Halkçılar deģil... Işte ancak o zaman toplumsal tarihe, "halkın" ana nitelił̆i olan "soğulcu" bir karakter kazandırabilir.

Bu tarihte, tekil siyasal kimlikler olabilir. Bunlar, devlet adlan ve aidiyetleriyle anılır. Ama, bu üst-kimliklerin aynasına, çokkültürlülügün prizmasından fişkıran farklı kimlik renkleri, topluma çoğulcu niteliğini yansıtur. Devletin bütün yapacał̆ı, bu gerçeğj gormek, tekil kimlik anlayışının renk kơrlưğüne düşmeden, bu renk cümbüşünden ahenkli bir siyasal tablo çıkarmakur. Bu tablonun bütünü toplum, çerçevesi devlet, renkleri ve figürleri birey ve kümelerdir. Siyaset (kaulma) ise, bu tabloyu yapan furçadir.

Birleştiricilik siyasette olmalıdır. Siyaset, külürel alandaki farklılıklan korurken, onların birarada yaşamasının koşullannı hazırlar, hazırlamalıdır. Siyasetin bas oznesi olan merkezi otorite tarafsız davranırken, bütün kültür kümelerinin birbirlerinin kimliklerine, inançlarına, yaşam tarzlarına, dillerine saygılı olmalarını sağlamalıdır. Iş̦te o zaman, vatandaşlar özel bir muamele istemezler. Tarafsız bir devlet de yurttaşlarına ayricalık veya azınlık statüsü tanımak durumunda kalmaz. Çünkü, tarafsız bir devlet, soy veya din temeline dayanmaz.

Böyle bir devlet yapısı, "aparuman" orneğine benzetilebilir. Her apartman, bir arsa (vatan) üzerine kurulmuştur. Herkesi içeren ve koruyan bir çatısı vardır (devlet). Apartmanın cari giderleri için daire sahipleri aidat oderler (vergi). Yönetici (hükümet) ve denetici(ler) (yasama organı) seçilerek işbaşına gelirler (demokratik yapı oluşur). Her dairenin sakinleri, apartmanın ortak yükümlülüklerini karşıladıklanı ve düzeni (asayişi) bozmadıkları sürece, diğer daire sahipleri tarafından rahatsız edilmezler. Bu ortak yaşam alanında özerk (ama bağımsız değil) bir hayat sürebilirler. Eğger bir devlete, "aparman yönetimi" özelliği kazandırılabilirse, bütünlǚgü (tckilliği) bozulmadan demokratik yaşam için ideal ortamı oluşturabilir.

Niteliği belirlenen "apartman devletin", bir "daire efradı" tarafından baskı ve tehditle yơnetilmeye başlanmasıyla ortaklık statüsü ve eşitlik biter, egemenlik ve tabiyet ilişkisi başlar. O zaman zorba daire sahibi, diğer sakinleri şiddet ve dehşet (terör) kullanarak "aparımandan" atmak ve yaşam alanlarını ele geçirmek isteyebilir. Bu durumda, tüm daire sahiplerinin ayñ keyfilikte ve zorbaca davranmak "hakkı" dołar. Oysa, zorbalık bir hak değildir, hak gaspıdır. Ama haksızlığa ve zorbalığa direnmek bir hakur. Bu hak, demokrasilerin özüdür. Birleşmiş Milletler Insan Haklan Evrensel Bildirisi, bu özü, insan haklarının dayanaklarından biri olarak benimsemiştir. Haklanın ve kimliklerini koruyabilmek için insanların örgütlenmeye ve bu savunmayı haklı kılabilmek için de hukukun güvencesine gereksinimleri vardır.

Hukuk, bireyleri ve kümeleri eşitleştirir. Bu nedenle, çok güçlủ olan devlet ơrgütünün, yurttaşlar ve alt-örgütlerle iliş̧kilerinde hukuk kurallarnna uygun hareket etmesi, toplumsal adalct açısından büyük önem taşır. Bir toplumda adalet duygusu yok olur ve toplumsal kümeler güvenlikleri ve kimlikleri konusunda endişeye düşerlerse, kendilerine güvenli yaşam alanları ararlar. Bu güveni ya aşkın güçlerde bulurlar. karizmatik onderlerin peşinde radikal dünyevi veya semavi akımlara kapılırlar. Ya da kendilerinc bağımsız küçük "vatanlar" yaratmak isterler. Bu arayışlar, etno-milliyetçilik, ayrilıkçılık, "yeni-kabilecilik" gibi sonuçlar doğurur. Her halûkarda, bőlünen, ayrı̧̧an toplumlar, kuşkunun, düşmanlıkların tutuşturduğu nefretin çah atcşiyle kan ve ateşe bulanırlar. Dünyanın büyük bir bölümü şimdi bőyle dramatik bir evreden geçiyor. 
Bütün insanlığın Tanrı'nın ailesi olduğu kabul edilirse, bu kardeş kavgasının bitmesi, bitirilmesi, hepimizin sorumlulugudur. Bunun da tek bịlinen yolu, eşitlik ve insan haklarına dayanan çogulcu demokrasidir. Hangi korku veya çıar nedeniyle demokrasi ve banı̧ın oluşmasına direnenler varsa, onlar sadece insanlık suçu değil, günah da işliyorlar demektir. 